\title{
Environments for the development of disease management competencies of children with diabetes mellitus: Children's experience
}

\author{
Vida Gudzinskiene and Indre Cergelyte-Podgrusienei \\ Mykolas Romeris University, Vilnius, Lithuania
}

\begin{abstract}
Type 1 diabetes mellitus alters the child's and their parents' life. The child must acquire necessary competencies that would help manage the disease. The child with diabetes mellitus can receive information from a variety of learning environments. Research object is - environments for the development of disease management competencies of children with diabetes mellitus. Research aim is to reveal environments for the development of disease management competencies of children with diabetes mellitus by highlighting what helps a child with diabetes to acquire disease management competencies, and the challenges occurring while acquiring those competencies. Research methods: theoretical - analysis, comparison and generalization of scientific literature; empirical - a semistructured interview method has been used for the collection of data; method of content analysis has been applied for the study of research data. Participants of the research were children with diabetes mellitus. The empirical study revealed that environments for the development of disease management competencies of children with diabetes mellitus are the following: environment of medical institutions and the professionals working there, family environment (family members), and the environment of camps for children with diabetes mellitus, including organizers of camps and specialists and volunteers invited. The research determined challenges of developing disease management competencies of children with diabetes mellitus in various learning environments.
\end{abstract}

Key words: type 1 diabetes mellitus, disease management, environments for competence development.

\section{Introduction}

Diabetes mellitus is a chronic metabolic disease characterized by impaired absorption of glucose in the body. This disease is incurable and medication is required to survive [1]. Diabetes mellitus is becoming a global epidemic: in 2011, 366 million people worldwide had diabetes, and it is projected that in 2025, 439 million people will have this disease. The incidence of type 1 diabetes mellitus in children is also increasing, in 2014 there were 500.000 children less than 15 years of age with this disease [1]. In Europe, there are over 60 million people suffering from diabetes mellitus. Europe has the highest incidence of type 1 diabetes, which is the most common in children. In order to control diabetes mellitus effectively, it is crucial for patients to follow recommendations of healthcare professionals. By adhering to the healthy lifestyle principles and treatment recommendations, patients can control their disease, avoid possible consequences and live full life [2]. Poor control of type 1 diabetes mellitus can lead to chronic complications that disrupt the normal life of a child [3]. Authors [4,5] note 
main complications of chronic diabetes mellitus, such as retinal damage - retinopathy, kidney glomerular damage - nephropathy (develops due to malnutrition, as the disease progresses may cause damage to kidneys). Large and small blood vessels can be damaged due to poor blood glucose control. Lesions in large blood vessel cause damage to the blood vessels in legs, as well as myocardial infarction, and cerebrovascular insult. Lesions in small blood vessels cause a variety of damages.

Development of health competence is important for children with diabetes mellitus. Their health knowledge and skills that determine child's behaviour in future are provided: the child consciously knows and understands what diabetes mellitus is, how to eat properly and monitor blood glucose, what normal physical activity should be, what to do and how to take care to avoid complications. Thus, health education can change behaviour of a child with diabetes mellitus for their well-being $[4,6,7]$.

For the child with diabetes it is important to create the most favourable environments for the development of disease management skills/competencies. According to researchers [8, 9], educational environment in the community, favourable to the development, is characterized by self-control, self-government and critical thinking. Children, provided with a favourable collaboration-based learning environment, are able and like to discuss and share ideas, education is a value to them. They have organizational and creative abilities; they feel responsibility for their own learning and behaviour [10]. Having analysed the development of social competencies of children, R. Larson (2000) notes that the social competencies develop when conditions for self-expressions are created, and children can decide for themselves.

The scientific problem implies a question: what environment creates preconditions for a child with diabetes mellitus to acquire competencies of disease management? Accordingly, the following article seeks to reveal environments for the development of disease management competencies of children with diabetes mellitus by answering the problematic question: how does a child with diabetes mellitus acquire disease management competencies? Who helps a child with diabetes mellitus acquire competencies of disease management? What challenges does a child face while acquiring disease management competencies?

Research object is environments for the development of disease management competencies of children with diabetes mellitus.

Research aim is to reveal environments for the development of disease management competencies of children with diabetes mellitus, highlighting who helps them to acquire disease management competencies and what challenges they face while acquiring the following competencies.

Research methods. Theoretical: analysis, comparison and generalization of scientific literature; empirical-a semi-structured method of interview has been used for the collection of data; method of content analysis has been applied for the study of research data.

Research questions:

1. What are the environments for the development of disease management competencies of children with diabetes mellitus?

2. Who helps a child with diabetes mellitus to acquire disease management competencies?

3. What challenges does one face in managing the disease?

\section{Research methodology}

Research methods. Qualitative research type was chosen for the study. According to Žydžiūnaitė \& Sabaliauskas (2017), the purpose of a qualitative study is to research - to reveal environments for the development of disease management competencies of children with diabetes mellitus. The method of semi-structured interview was used in the study. This article 
overviews problematic question of the study: "what are the environments for the development of disease management competencies of children with diabetes mellitus? Who helps a child with diabetes mellitus to acquire disease management competencies? What challenges does one face in managing the disease?" The obtained data were analysed by using the content analysis method. The qualitative content analysis was made in the following sequence: the repeated reading of the content of transcribed interview texts, the distinction of meaningful elements in the text analysed, the grouping of the distinguished meaningful elements into categories and sub-categories, integration of the categories/sub-categories into the context of the phenomenon analysed and the description of their analysis [11].

P. Mayring (2000) emphasises that content analysis is a valid method for making specific inferences from the analysed text.

The sample of research. The study used a criteria-based sample. The respondents were chosen according to the following criteria: 1) children with Diabetes Mellitus; 2) children who suffer from diabetes from the age of 7 to the age of $15 ; 3$ ) children who found out about the disease at least one year ago. The study was conducted between February and May of 2019. The duration of an interview lasted from 35 to 60 minutes. Six children with Diabetes Mellitus participated in the qualitative research. The age of research participants ranged from 10 to 13 years. The research was attended by 4 girls and 2 boys.

Ethics of the research. Parents of children who participated in the research, as well as children themselves were familiarised with the goal of the research, the interview questions, and the importance of a reasoned reflection on their experience. A parental consent of all research participants was obtained, allowing their children to participate in the research, including the agreement of parents and children to record the interview into a voice recorder. During the research, its ethics complied with the following essential principles [19]: 1) The right not to be vulnerable, which means not to make any negative impact on their physical, mental and social health; 2) The right not to be abused, ensuring that participation of research participants and information provided to them will not be used against them; 3) Usefulness of the research-the research participants wilfully agreed to participate in the research. Their participation in a specific research makes a positive impact on the development of society and knowledge; 4) Respect for personal dignity - the research participants were interpreted as independent persons, who were able to control their personal behaviour; 5) Every research participant had the right to make a personal decision whether to participate in the research or not; 6) Justice - such factors as the benefit, credulity or compromise were not used in order to involve the "necessary" persons in the research. The participants had the opportunity to ask about the research and receive comprehensive information. The research participants were treated in a respectful and helpful manner; 7) Confidentiality - the research participants were assured that information provided during the research (the collected qualitative data) will not be disseminated; the unprocessed information will not be available to any person, who is not related to the thesis and, specifically, to the exploratory part of the thesis; 8) Anonymity - the research participants were assured that their provided accurate personal data would not be published without coordinating such possibility in advance. In order to maintain confidentiality, respondents were encoded in letters A, B, C, D, E and F.

\section{Acquisition of disease management competencies of children with diabetes mellitus}

Diabetes mellitus is one of the chronic diseases that are incurable and overtime other organs in the body begin to strike [12]. One of the key aspects is to prevent complications or at least delay them. It is noteworthy that a child with diabetes mellitus and their parents need health 


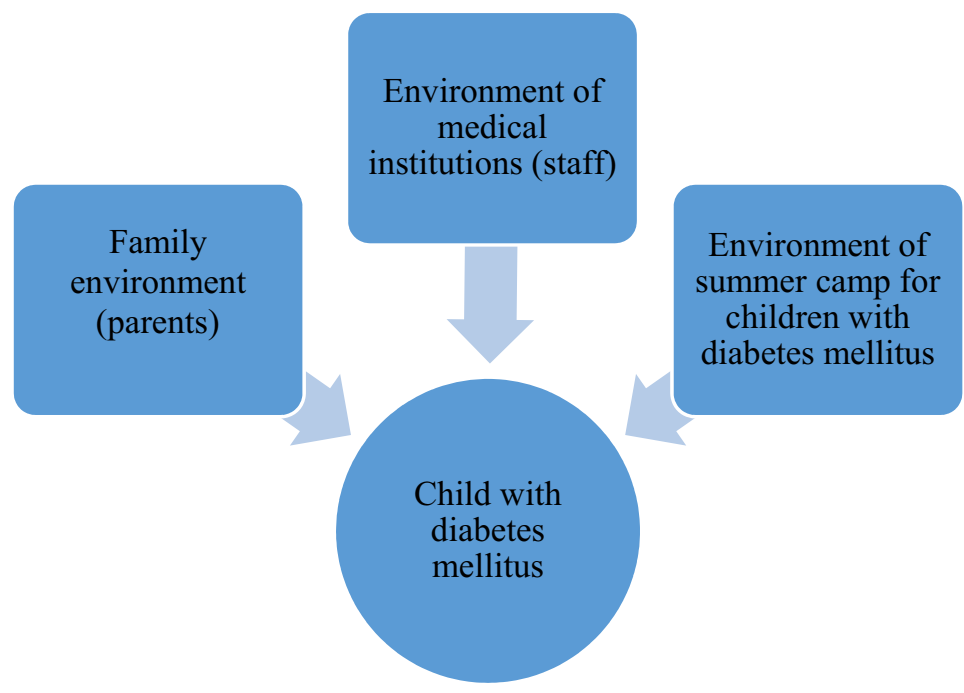

Fig. 1. Environments for the development of disease management competencies of children with diabetes mellitus. Compiled by the author on the basis of children's experiences.

knowledge and skills that help to manage diabetes mellitus and enable the child to take care of their own health [13].

In order to reveal opportunities for children with diabetes mellitus to acquire disease management competencies, as well as environments for the development of these competencies, informants were asked: "where did you get necessary information about the disease management competencies?" The following manner of presenting the question was chosen for all respondents to understand the question in the same way. The analysis of the informants' responses revealed that the environments for the development of disease management competencies of children with diabetes mellitus are the following: family environment of the child, environment of medical institutions where the child is treated, and the environment of summer camps for children with diabetes mellitus and their parents (Fig. 1).

Research revealed that one of the environments for the development of disease management competencies of children with diabetes mellitus is the environment of medical institutions where the child is treated. Informants noted that one of the first environments, where they began to develop disease management competencies, was a medical institution: "when I checked into hospital, it was the staff of the medical institution." "I think I've acquired in the hospital... from doctors, and diabetes doctor... also nurses... they and my parents told me what diabetes is, why it occurs, how to take proper care of my health condition. They told me about healthy diet, I mean what foods to eat having diabetes and what to avoid... but I was younger when I got diabetes, so I remember that much..." (A), “... as far as I remember, when I was in Kaunas clinics, there were all sorts of lessons there, where a diabetes nurse taught us how to correctly inject insulin, showed us the sites for injection, also told us about carbohydrates, what carbohydrates are, about food products, what we can eat. Hmmm. .. she also told us about sugar levels and what they should be... the doctor also told a lot about my medical results..." (E), “... diabetes nurse told me a lot, she was very nice... really very nice, always with a smile, I really liked her... and she told me about healthy diet, how to combine food so that sugar levels would not jump, as well as about insulin - what it is, why to inject it, and the sites for injection..." $(F)$. Researchers 
[14] emphasize that doctors and nurses must have necessary skills to convey knowledge of diabetes mellitus not only to parents, but also to the child, and it is important to make contact because it affects the management of disease.

Moreover, research revealed that children acquired disease management competencies from the family environment (parents) - “...my mom tells me everything... what to eat... when to measure sugar level... what is prohibited...my mom teaches me everything and I try to remember everything...” (B), “... my mom tells me everything, what food products to eat, how to count carbohydrates correctly and how much of them I can eat, my mother also tells me to maintain personal hygiene (brush my teeth, take a shower and examine my skin for any wounds... and my mom always gives advice... she knows everything and teaches me..." (F), “...my mom and dad provide me knowledge about my diseases, because they know everything... of course I also should know a lot, because I have it, so my mammy and dad teach me how to eat right, what products to choose, how to behave in school, when to inject insulin and when to measure blood sugar..." (C). It should be noted that foreign authors $[15,16]$ emphasize that parental concern and excessive desire to help their child (protect one) can worsen the situation, as the child becomes less independent and does not know how to take proper care of their own health; thus, parents should engage their children into the learning process. For a child, their parents and family members are the most influential and closest environment for the development of disease management competencies of a child with diabetes mellitus, where the child not only develops disease management competencies, but also avoids crisis: "well, I sometimes forget to eat... or to measure blood sugar, and my parents remind me..." (B), "It happens at home that I get carried away with playing and forget everything, well I mean to inject insulin, so my mom reminds me and tells me it's time to do it..." $(F)$. On the other hand, it is worth noting that successful cooperation between parents and children in developing disease management competencies is only possible through the dialogue, when parents and children act as an indivisible whole. "You see, it's me and parents, my whole family is interested in me managing the disease" (A), “...that I do everything on time, that I avoid eating what is unnecessary, that I eat on time. . all these things are important for me and my parents... ” (D). Therefore, the development of disease management competencies of children with diabetes mellitus is inseparable from their learning at home. Children receive basic knowledge at medical institutions, but disease management, as well as other health-friendly skills and habits are formed and embedded in the family environment, where the foundation of personality is formed.

A child with diabetes mellitus needs to form a sense of independence in order to lead full, qualitative life in the future by caring for their health. Thus, it is favourable to develop the sense of independence not in the family environment, but in other, in this case, children with diabetes mellitus related camps, where the child independently develops necessary skills that help to maintain health [17]. Informants of the research indicated that they have acquired disease management competencies in the summer camp environment. "... I like camps... People like me gather there and we talk, well, we talk about how we are holding up, how we manage at school, what sports activities we engage in and, of course, we learn together, because there are different lessons at the camp on how to keep sugar from jumping up and down, how to focus, how to behave at school... I learn a lot..." (C). “... There are summer camps, and it's there that we play with friends and do sports, because there are exercises every morning, sometimes we play some volleyball, it's a lot of fun, we actively spend time and attend lessons about insulin, pumps, about healthy diet, sports, about innovations... I really like it..." (B). "At summer camps you not only find friends, who give advice and help to accept the disease, but you also try to manage the disease by yourself." 


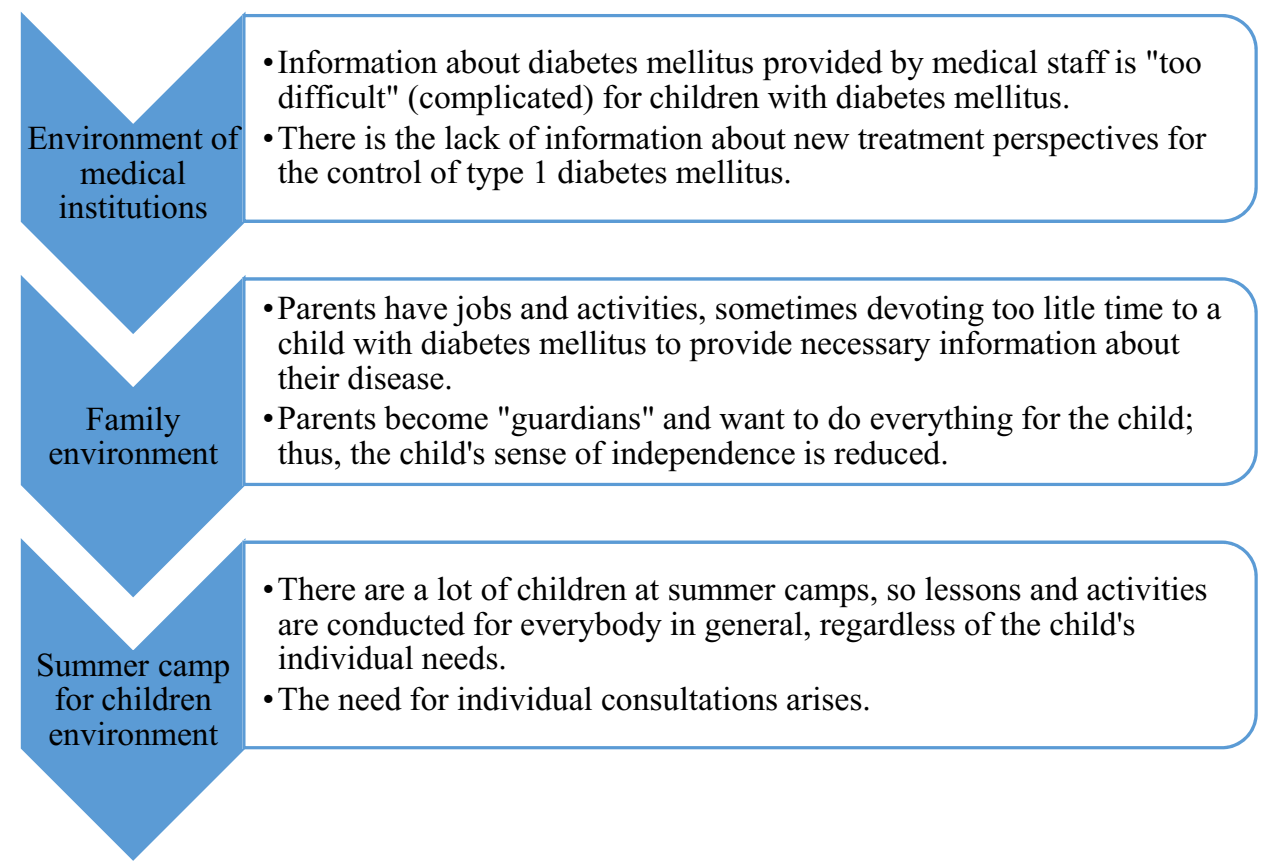

Fig. 2. Challenges of the development of disease management competencies of children with diabetes mellitus in their learning environments. Compiled by the author on the basis of children's experiences.

(D). "It's just when you see that you can play, have fun, you understand that by acting responsibly you can control everything by yourself." $(F)$. Accordingly, the third environment for the development of competencies that has become evident during the research is the environment of summer camps for children with diabetes mellitus. Communication among children with diabetes mellitus helps to make friends with the disease [18].

The summary of responses of study participants allows us to claim that children with diabetes mellitus receive required information about the disease management from the environment of medical institutions and in the family environment. Parents help children acquire necessary information and skills to manage the disease; whereas by eagerly participating in summer camps for children with diabetes mellitus, children meet with their friends, get stronger morally, and, eventually, accept responsibility for the management of the disease. Therefore, the summer camp environment contributes not only to the development of independence, but also to the development and consolidation of an attitude to accepting responsibility for the disease.

\section{Challenges of the development of disease management competencies of children with diabetes mellitus in their learning environments}

The research also revealed that not everything is going smoothly and each of the already discussed environments presupposes certain obstacles/challenges that have a negative impact on the development of disease management competencies of children with diabetes mellitus (Fig. 2). 
Accordingly, medical institutions must ensure treatment of the disease and provision of necessary information for children with diabetes mellitus and their parents. Children with diabetes mellitus should firstly receive information about their disease from medical institution (nursing staff), but it is not always possible due to the lack of time or employment. The research revealed that one of the challenges of developing disease management competencies of children with diabetes mellitus in the environment of medical institutions is that information is provided "medically": "sometimes you don't understand everything what the doctor says, as they speak in terms and it's complicated..." (A), "I believe it could be explained in simple words what diabetes mellitus is, because I don't understand everything" (B). Another problem/obstacle in the environment of medical institutions mentioned by the informants is that they lack new information about the disease control: "Well, I don't know, it would be interesting to know how everything is abroad, what has changed, because I have diabetes for 3 years now... " (C), "perhaps I would like to acquire new knowledge, for example, about insulin pumps" (D). Taking the aforementioned into account, medical institutions should provide trainings for medical staff on how to inform children with diabetes mellitus properly and comprehensively. They should know how to apply active learning methods while presenting information for children about means of managing the disease. As the informants mentioned, obstacles in the environment of medical institutions relate to the lack of pedagogical training of healthcare staff. Though they have enough information, the inability to convey properly that information to children of different ages makes it incomprehensible/inaccessible for the recipients.

Family environment - parents/adoptive parents/guardians and other family members - is important for the process of learning of the child with diabetes mellitus, because one's family is the closest environment, where the child spends most time. Informants mentioned that main obstacle in the family environment is parental employment: "well, my parents work and sometimes don't have time to tell me more about my disease" $(F)$, "there is not always time left for me, because parents have what to do, so it depends..." (D). Parents are responsible for the child and their well-being. Thus, when a child is diagnosed with diabetes mellitus, parents try to convey all the knowledge they have about the disease to make it easier for the child to accustom to it. However, sometimes the desire to control the child and help them, makes the child avoid responsibility for themselves and their disease, and their sense of independence disappears: "my mom does everything for me, she controls everything and wants to know, because that makes her calmer..." (E), "my mother chooses food for me to eat and tells me when I need to measure my blood sugar and when to inject insulin..." $(F)$, "parents, they put it all together, what my agenda with diabetes will be..." (A). Nevertheless, parents must help develop habits and skills that guarantee the control of disease management, since the priority in the learning process falls on the family as the most important social institution, where a person experiences the first and most important socialization. The family is not an auxiliary institution that seeks to create and maintain structures and relationships existing in the state, but the key condition for the realization of the human potential. It is an institution with unique opportunities, great influence on the social formation and development of a personality.

The research identified another environment where the child acquires skills of disease management, summer camps for children with diabetes mellitus. The research revealed that children positively assess the summer camp environment in terms of competencies that lead to disease management. They indicated many advantages and only one obstacle or an issue to be improved: "well, lessons and activities are organized for everybody in general...we would like the organizers to pay more attention to the individual needs of the child" (B), "More individualized activities..." (E). 
Therefore, with due regard to the acquisition of health knowledge and skills on how to properly manage diabetes mellitus, organizers and volunteers at summer camps should devote time for individual consultations to meet individual needs of camp participants. The environment of the summer camp must be physically and psychologically suitable for children with diabetes mellitus; it must ensure health, cooperation between children and their parents, and facilitate exchange of available information and sharing of experiences, but it should also facilitate individual consultations with specialists. In addition to specialists, there are volunteers at summer camps, trained in how to behave with a child with diabetes mellitus. Thus, volunteers help to establish an agenda and carry out procedures needed to manage the disease.

Drawing on the environment of medical institutions and advice provided by professionals working there, cooperation with parents and other family members (family environment), as well as exchange of experiences with other children with diabetes mellitus and their parents, the child has the opportunity to acquire competencies of disease control/management. However, no less important issue for the children is to understand clearly that it is impossible to acquire daily habits, which would help to manage the disease without their own efforts. They should understand their own inner disposition: eat according to recommendations provided by specialists, follow a proper daily routine, be physically active, take care of proper dosing of medicines, maintain personal hygiene, take care of their skin, and monitor blood sugar. The child must take care, protect and nurture their health as the greatest value.

\section{Conclusions}

Environments for the development of disease management competencies of children with diabetes mellitus are the following: environment of medical institutions and specialists working there, family environment (family members), and camp environment for children with diabetes mellitus, including camp organizers and invited specialists and volunteers. Every mentioned environment contributes to the development of disease management competencies of children with diabetes mellitus. Priority in the learning process is given to the family as the most important social institute.

The research revealed challenges of the development of disease management competencies of children with diabetes mellitus in various learning environments. The research determined that specialists working in the environment of medical institutions provide information too "medically", and children cannot understand and accept it properly, because medical staff speaks in terms that are incomprehensible to children. Another obstacle for the acquisition of disease management competencies of children in the environment of medical institutions mentioned by informants is the insufficiency/lack of new information on disease control.

The main obstacle for the development of disease management competencies in children in the family is parental employment or their "guardian" attitude; parents' desire to control and help the child is so great that the child begins to avoid responsibility for them and their disease, their sense of independence disappears.

The research revealed that children positively assess the summer camp environment in terms of competencies of disease management, believe that there are many advantages. They identified only one area for improvement: to devote more time to individual consultations with specialists in order to meet the individual needs of camp participants. 


\section{References}

[1] T. Li, Y. Jia, S. Wang, L. Gao, C. Yang, H. Zou, Retinal Microvascular Abnormalities in Children with Type 1 Diabetes Mellitus Without Visual Impairment or Diabetic Retinopathy 60, 990-998 (2019)

[2] S. Frye, M. Perfect, G. Silva, Diabetes management mediates the association between sleep duration and glycemic control in youth with type 1 diabetes mellitus 60, 132-138, (2019)

[3] G.R. Sousa, D. Pober, A. Galderisi, L. Yu, A.C. Pereira, A. Doria, M. Kosiborod, M.A. Lipes. Circulation. Glycemic Control, Cardiac Autoimmunity, and Long-Term Risk of Cardiovascular Disease in Type 1 Diabetes Mellitus 139, 730-743 (2019)

[4] M.M. Nentwich, M.W. Ulbig, Pubmed. Diabetic Retinopathy - Ocular Complications of Diabetes Mellitus 15:6(3), 489-499 (2015)

[5] M.L. Marcovecchio, R.N. Dalton, D. Daneman, J. Deanfield, T.W. Jones, H.A. Neil, D.B. Dunger, A new strategy for vascular complications in young people with type 1 diabetes mellitus 15, 429-435 (2019)

[6] A.L. Brorsson, J. Leksell, M.A. Franko, A.L. Olinder, A person-centered education for adolescents with type 1 diabetes - A randomized controlled trial 20(7), 986-996 (2019)

[7] L. Litchfield, R.C. Andrews, P. Narendran, S. Greenfield, Fronties in endocrinology. Patient and Healthcare Professionals Perspectives on the Delivery of Exercise Education for Patients with Type 1 Diabetes 10(76), 1-10 (2019)

[8] K.A. Brown, A.A. Schainker, Journal of Cases in Educational Leadership. Doing all the right things 11(1), 10-17 (2008)

[9] R.M. Berns. Vaiko socializacija (Vilnius, Poligrafija ir informatika, 2009)

[10] K.B. Everard, G. Morris, Effective School Management - fourth edition (London, Educology, 2004)

[11] V. Žydžiūnaitè, S. Sabaliauskas, Kokybiniai Tyrimai - Principai ir Metodai (Vilnius, Vaga, 2017)

[12] S.A. Amiel, P. Aschner, B. Childs, P.E. Cryer, B.E. Galan, B.M. Frier, L. GonderFrederick, S.R. Heller, T. Jones, K. Khunti, L.A. Leiter, Y. Luo, U. PedersanBjergaard, E.R. Seaquist, S. Zoungas, Pubmed. Hypoglycaemia, Cardiovascular Disease, and Mortality in Diabetes: Epidemiology, Pathogenesis, and Management 7(5), 385-396 (2019)

[13] E. Lambrinou, T.B. Hansen, J.W.J. Beulens, European Journal of Preventive Cardiology. Lifestyle factors, self-management and patient empowerment in diabetes care 26(2), 55-63 (2019)

[14] A. Alotaibi, L. Gholizadeh, A. Al-Gamni, L. Perry, Nursing research. Examining perceived and actual diabetes knowledge among nurses working in a tertiary hospital 35, 24-29 (2017)

[15] A. Tomette, J.N. Henderson, A. Hass, L.D. Carson, K. King, Parental Stress as a Child with Diabetes Transitions from Adolescence to Emerging Adulthood, Sage journal 2, 1-7 (2019)

[16] V. Davis, S.B. Telang, S. Jain, M.W.D. Ramos, M.A. Ward, I. Jindal, J.R. Aschkenasy, C.M. Glover, R.C. Shah, Clin diabetes. Parental Perception of the Factors That Affect Diabetes Management in Youth 37(1), 50-56 (2019)

[17] I. Čergelytė-Podgrušienè, V. Gudžinskienè. Possibilities of acquiring competencies in disease management of children with diabetes mellitus. Sabiedriba. Integracija. Izglitiba $=$ Society. Integration. Education: Lifelong learning information technologies 
in education: proceedings of the international scientific conference, May 22-23, 2020. Rēzekne: Rēzeknes Tehnoloìiju akadēmija VI, 171-180 (2020)

[18] A. Tomette, J.N. Henderson, A. Hass, L.D. Carson, K. King, Parental Stress as a Child with Diabetes Transitions from Adolescence to Emerging Adulthood, Sage journal 2 1-7 (2019) 